\title{
Osteoblast Differentiation and Disinfection Induced by Nitrogen Plasma-treated Surfaces
}

Wei Zhang ${ }^{\mathrm{a}, \mathrm{b}, \mathrm{c}}$, Huaiyu Wang ${ }^{\mathrm{b}}$, Ayako Oyane ${ }^{\mathrm{a}}$, Hideo Tsurushima ${ }^{\mathrm{a}}$, Paul K. Chu ${ }^{\mathrm{b}}$

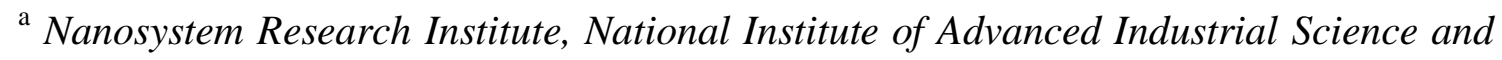
Technology (AIST), Tsukuba, Japan

${ }^{\mathrm{b}}$ Department of Physics \& Materials Science, City University of Hong Kong, Hong Kong, China

${ }^{\mathrm{c}}$ Technical Institute of Physics and Chemistry, Chinese Academy of Sciences, Beijing, China

To whom correspondence should be addressed; Hideo Tsurushima, Department of Neurosurgry, Graduate School of Comprehensive Human Science, University of Tsukuba, Tennoudai 1-1-1, Tsukuba, Ibaraki 305-8575, Japan, E-mail: hideotsurushima@md.tsukuba.ac.jp Phon: +81-29-853-3220 Fax: +81-853-3214

Running Head: Nitrogen Plasma-treated Surfaces for Tissue Engineering 


\begin{abstract}
Plasma technology is widely employed to tailor the surface chemistry of polymeric biomaterials. In this work, nitrogen-containing functional groups were generated on a polymer surface by $\mathrm{N}_{2}$ plasma immersion ion implantation (PIII). We evaluated the abilities of the resulting surface to inhibit bacterial growth and to enhance osteoblast differentiation from the perspective of bone tissue engineering. Our results demonstrate that the $\mathrm{N}_{2}$ PIII-treated polymer surface exhibits antibacterial properties against Escherichia coli. Moreover, the $\mathrm{N}_{2}$ PIII-treated polymer surface has the ability to enhance differentiation of osteoblasts. N2 PIII-treated polymer surface may therefore be useful in bone tissue engineering.
\end{abstract}

Keywords: bone tissue engineering, differentiation, disinfection, osteoblasts, plasma, polymer 


\section{Introduction}

Recent research in tissue engineering has been focused on the chemistry of the material surface that regulates specific signaling pathways and controls cellular functions [1,2]. Among the various technologies used to tailor the surface chemistry, gas plasma treatment is relatively simple and is widely employed to modify a polymer surface and to render different properties. Careful control of the processing parameters can modulate the chemical specificities of the polymer surface, enabling the polymer to cater to a particular application [3-5].

A $\mathrm{N}_{2}$ plasma is typically composed of various nitrogen radicals, such as $\mathrm{N}_{2}, \mathrm{~N}_{2}$ (excited), and $\mathrm{N}$ [6]. It is possible to produce nitrogen-containing functional groups, such as $\mathrm{C}-\mathrm{N}, \mathrm{C}=\mathrm{N}, \mathrm{N}-\mathrm{O}, \mathrm{N}=\mathrm{C}-\mathrm{O}$, and $\mathrm{N}-\mathrm{C}=\mathrm{O}$, on a polymer surface using the $\mathrm{N}_{2}$ plasma [4-6]. In this work, we generate nitrogen-containing functional groups on a polymer surface by $\mathrm{N}_{2}$ plasma immersion ion implantation (PIII), and then evaluate the ability of $\mathrm{N}_{2}$ PIII-treated polymer surface to inhibit bacterial growth and to enhance osteoblastic cell differentiation. Although plasma technology has been widely used to modify the surface chemistry of polymers, very little is known about influences of the $\mathrm{N}_{2}$ plasma-generated functional groups on osteoblastic cells. In this study we indicated the potential of $\mathrm{N}_{2}$ PIII-treated polymer surface in bone tissue engineering. 


\section{Materials and methods}

\subsection{Sample Preparation}

Polyethylene (PE, Mw $=9$ x $10^{4}$ g/mol, Beijing Huaer Co., Ltd., China), which possesses a simple chemical structure, was chosen as the polymer in our study to more easily understand the surface chemical changes arising from the $\mathrm{N}_{2}$ PIII treatment. The more common $\mathrm{O}_{2}$ PIII treatment was also applied as the control. PE samples with dimensions of $10 \mathrm{~mm} \times 10 \mathrm{~mm} \times 1 \mathrm{~mm}$ were subjected to the PIII treatments using the following conditions based on previous studies [4,5]: bias voltage $=-5 \mathrm{kV}$, radio frequencypower $=1000 \mathrm{~W}$, treatment time $=10 \mathrm{~min}$, gas pressure $=5 \times 10^{-5}$ torr, $\mathrm{N}_{2}$ or $\mathrm{O}_{2}$ flow rate $=10 \mathrm{sccm}$. The untreated PE, $\mathrm{O}_{2}$ PIII-, and $\mathrm{N}_{2}$ PIII-treated PE samples are denoted as PE control, $\mathrm{O}_{2}$ PIII-treated polymer surface, and $\mathrm{N}_{2}$ PIII-treated polymer surface, respectively. The prepared samples were stored in a vacuum chamber before the surface characterization.

\subsection{Surface Characterization}

Contact mode atomic force microscopy (AFM, Nanoscope III, Digital Instruments Co., USA) was used to observe the surface morphology and to measure the surface roughness of the samples (scanned area was $4 \mu \mathrm{m} \times 4 \mu \mathrm{m}$ ). The static contact angles associated with distilled water for the samples were determined at ambient humidity and temperature using Ramé-Hart contact angle goniometry (Ramé-Hart instrument Co., USA).

The surface chemical states of the samples were examined by X-ray photoelectron spectroscopy (XPS, PHI 5802, Physical Electronics Inc., USA) 
employing monochromatic $\mathrm{Al} \mathrm{K} \alpha$ radiation operated at $14 \mathrm{kV}$ and $350 \mathrm{~W}$. The same kind of samples was measured at three different points. All XPS data fitting was performed using $100 \%$ Gaussian line shapes with a Shirley background subtraction.

\subsection{Antibacterial assay}

The antibacterial performance of the samples against Escherichia coli (E. coli) was assayed using a standard colony counting method [7]. In brief, $0.1 \mathrm{~mL}$ of $1 \times 10^{5}$ CFU/mL E. coli suspensions was applied to the surface of each sample. After incubation for 24 hours at $37 \pm 1{ }^{\circ} \mathrm{C}$ with a relative humidity higher than $90 \%$, the $E$. coli cultures were transferred onto a Lysogeny Broth plate and incubated for another 24 hours. After incubation the viable colonies on the plate were counted.

\subsection{Cell Culture}

A mouse osteoblastic cell line (MC3T3-E1) derived from hamsters (RIKEN BioResource Center, Japan) was incubated in a minimal essential medium (invitrogen, USA) supplemented with $10 \%$ fetal bovine serum (invitrogen, USA). One ml cell suspension was seeded on each sample in the well of a 24-well cell culture plate and incubated at $37^{\circ} \mathrm{C}$ in $5 \% \mathrm{CO}_{2}$ for varying periods of time.

2.5. Detection of Alkaline Phosphatase (ALP) and Osteocalcin (OC) expressions with real-time PCR

One $\mathrm{ml}$ of $5 \times 10^{4}$ cell/mL cell suspension was applied to each sample in a 24well cell culture plate. After incubation for 4 days, in vitro cell samples were washed 
three times with phosphate buffered saline (PBS). Total RNA was extracted from these samples with an RNA extraction kit (Invitrogen, USA). One microgram of total RNA was reverse transcribed in a buffer containing $1 \mu \mathrm{L}$ oligo-dT primers (2.5 M), $250 \mu \mathrm{M}$ deoxynucleotides, 10 U RNasin (Promega, Japan), and 100 U Superscript II (GIBCOBRL, USA?). This mixture was incubated for $40 \mathrm{~min}$ at $42{ }^{\circ} \mathrm{C}$ and then for $5 \mathrm{~min}$ at $95{ }^{\circ} \mathrm{C}$. The expression levels of ALP, OC, and GAPDH were detected using the following primers: forward primer 5'-GAGCAGGAACAGAAGTTTGC-3' and reverse primer 5'-GTTGCAGGGTCTGGAGAGTA-3' for ALP [8], forward primer 5'AGCTCAACCCCAATTGTGAC-3' and primer 5'AGCTGTGCCGTCCATACTTT-3' for OC [8], and forward primer 5'AАСТСССАТТССТССАССТТ-3' and reverse primer 5'GAGGGCCTCTCTCTTGCTCT-3’ for GAPDH [8]. Each primer (12.5 pM) along with 0.5 ?L of template sample was added to a solution containing $12.5 \mu \mathrm{L}$ of iQ SYBR green supermix (Bio-Rad, Japan) (final volume: $25 \mu \mathrm{L}$ ). The expression levels of $A L P$, and $O C$ were indicated as the delta cycle times ( $\triangle$ cycle $(\mathrm{t}))$ compared with GAPDH expression.

\subsection{ALP Activity and OC Assay}

One $\mathrm{ml}$ of $5 \times 10^{4}$ cell/mL cell suspension was applied to each sample in a 24well cell culture plate. After incubation for varying periods, in vitro cell samples were washed three times with PBS. The cells were lysed by freezing and thawing for three cycles in $200 \mu \mathrm{L}$ of $1 \%$ triton X-100 in ultrapure water. The cell lysate solutions were 
centrifuged at $2000 \mathrm{~g}$ for $10 \mathrm{~min}$ at $4{ }^{\circ} \mathrm{C}$. The supernatants were stored at $-20{ }^{\circ} \mathrm{C}$ prior to analysis of the total protein content, ALP activity assay and OC assay.

The ALP activity of the cell lysate supernatants after 4, 7, and 9 days incubation, was assayed using p-nitrophenylphosphate as a substrate by employing an ALP activity kit (Wako Co., Japan). The absorbance of the solution at $405 \mathrm{~nm}$ was measured using the microplate reader (Bio-Rad Laboratories Inc., USA). The levels of ALP activity were normalized to the total cellular protein content.

The cell culture medium obtained after 4 and 9 days incubation was centrifuged at $2000 \mathrm{~g}$ for $10 \mathrm{~min}$ at $4{ }^{\circ} \mathrm{C}$. Quantification of OC in the supernatants was performed using a mouse OC EIA kit (Biomedical Technologies Inc., USA), according to its protocol. The absorbance of the solutions was measured at $450 \mathrm{~nm}$ using the microplate reader (Bio-Rad Laboratories Inc.). The levels of OC secretion were normalized to the total cellular protein content.

The quantification of protein in the cell lysate supernatants was performed using a micro-BCA protein assay kit (Thermo Fisher Scientific Inc., USA). The absorbance of the resulting solution at $570 \mathrm{~nm}$ was measured using a plate reader (Bio-Rad Laboratories Inc.).

\subsection{Statistical analysis}

All data was analyzed using the Student's t-test, and probability values of less than 0.05 were considered to be statistically significant. Experimental results are expressed as the mean \pm the standard error of the mean. 


\section{Results}

\subsection{Surface Characterization}

The AFM observation showed that both the $\mathrm{N}_{2}$ PIII-treated polymer surface and $\mathrm{O}_{2}$ PIII-treated polymer surface had little effect on the morphology of the surface; the measured root mean square (RMS) roughness was about $200 \mathrm{~nm}$ for all the samples (p > 0.05). In contrast, the $\mathrm{N}_{2}$ PIII-treated polymer surface and $\mathrm{O}_{2}$ PIII-treated polymer surface greatly improved the hydrophilicity of the PE control; water contact angle decreased from $94.83^{\circ} \pm 1.21^{\circ}$ to $37.93^{\circ} \pm 4.94^{\circ}$ and $28.53^{\circ} \pm 2.02^{\circ}$ by the $\mathrm{N}_{2}$ PIII-treated polymer surface and $\mathrm{O}_{2}$ PIII-treated polymer surface, respectively. The improvement in surface hydrophilicity may be attributed to the formation of polar groups on the PE surface that were induced by the $\mathrm{N}_{2}$ PIII and $\mathrm{O}_{2}$ PIII treatments [6].

Table 1 shows the element ratios of $\mathrm{O}$ and $\mathrm{N}$ to $\mathrm{C}$ on the surfaces of the samples; the results suggest that nitrogen- and oxygen-containing functional groups were generated on the PE surface by the $\mathrm{N}_{2}$ PIII and $\mathrm{O}_{2}$ PIII treatments, respectively. From the high resolution XPS spectrum of $C_{1 s}$ shown in Figure $1 b$, the oxygen-containing functional groups formed on the $\mathrm{O}_{2}$ PIII sample were identified as $\mathrm{C}-\mathrm{O}, \mathrm{C}=\mathrm{O}$, and $\mathrm{O}-$ $\mathrm{C}=\mathrm{O}$ [9]. From the high resolution XPS spectra of $\mathrm{C}_{1 \mathrm{~s}}$ and $\mathrm{N}_{1 \mathrm{~s}}$ shown in Figures $1 \mathrm{c}$ and $1 \mathrm{~d}$, the nitrogen-containing functional groups formed on the $\mathrm{N}_{2}$ PIII-treated polymer surface were identified as $\mathrm{C} \equiv \mathrm{N}, \mathrm{C}=\mathrm{N}, \mathrm{C}-\mathrm{N}, \mathrm{O}-\mathrm{C}-\mathrm{N}$, and $\mathrm{O}=\mathrm{C}-\mathrm{N}[6,9]$.

\subsection{Antibacterial Properties}

The $\mathrm{N}_{2}$ PIII-treated polymer surface sample showed better disinfectant property to E. coli than the PE control and $\mathrm{O}_{2}$ PIII-treated polymer surface. We observe that the 
number of viable $E$. coli on the $\mathrm{N}_{2}$ PIII-treated polymer surface was significantly lower than that on both the PE control and $\mathrm{O}_{2}$ PIII-treated polymer surface after 24 hours of incubation, as shown in Figure 2a. The $\mathrm{O}_{2}$ PIII-treated polymer surface exhibited no disinfectant properties.

\subsection{ALP and OC gene Expression}

ALP and OC expression level are two important indicators for the early and mature differentiations of osteoblasts [10]. The results in Figures $2 b$ and $2 c$ showed that the MC3T3-E1 cells had higher ALP and OC expression levels on $\mathrm{N}_{2}$ PIII-treated polymer surface compared with PE control and $\mathrm{O}_{2}$ PIII-treated polymer surface.

\subsection{ALP Activity and OC Assay}

The $\mathrm{N}_{2}$ PIII-treated polymer surface promoted the differentiation of the MC3T3E1 cells on its surface compared with the PE control and $\mathrm{O}_{2}$ PIII-treated polymer surface, according to the results of the ALP activity and OC assay. ALP activity is a marker for the early and mature differentiations of osteoblasts, and is also an indicator of bone formation and matrix mineralization [10]. Figure 2d shows that the MC3T3-E1 cells on the $\mathrm{N}_{2}$ PIII-treated polymer surface exhibited higher ALP activity than those on the PE control and $\mathrm{O}_{2}$ PIII-treated polymer surface at the incubation periods of 4 and 9 days.

The promoted differentiation of the MC3T3-E1 cells on the $\mathrm{N}_{2}$ PIII-treated polymer surface compared with the PE control was also confirmed by OC assay. OC secretion is another biological marker for terminal differentiation of osteoblasts. As shown in Figure 2e, the MC3T3-E1 cells on the $\mathrm{N}_{2}$ PIII-treated polymer surface 
secreted a significantly larger amount of OC than did those on the PE control at the incubation period of 4 days. Differences in OC secretion between the $\mathrm{N}_{2}$ PIII-treated polymer surface and $\mathrm{O}_{2}$ PIII-treated polymer surface were not statistically significant. 


\section{Discussion}

$\mathrm{N}_{2}$ plasma is composed of many species of nitrogen radicals [6], which collide and react with polymeric chains on the polymer surfaces when a bias voltage is applied. The chemical and physical characteristics of the polymer surface can be tailored, depending on the treatment conditions (type of gas, pressure, temperature, treatment time, and the source power). In the present work, the $\mathrm{N}_{2}$ and $\mathrm{O}_{2}$ PIII treatments were applied to PE based upon our previous studies [4,5]. XPS analysis indicated that nitrogen-containing functional groups were formed on the $\mathrm{N}_{2}$ PIII-treated polymer surface, and oxygen-containing functional groups were formed on the $\mathrm{O}_{2}$ PIII-treated polymer surface (Table 1 and Figure 1) [6,9]. The nitrogen-containing functional groups on the $\mathrm{N}_{2}$ PIII-treated polymer surface also contained oxygen, as indicated by XPS (Table 1). Co-existence of oxygen in these groups can be attributed to oxidation of less stable nitrogen-containing functional groups by atmospheric oxygen-containing species after the $\mathrm{N}_{2}$ PIII treatment. For example, imine groups formed on the surface may be converted by the following reaction: $\mathrm{R}-\mathrm{CH}=\mathrm{NH}+\mathrm{H}_{2} \mathrm{O} \rightarrow \mathrm{R}-\mathrm{CH}=\mathrm{O}+\mathrm{NH}_{3}$.

The $\mathrm{N}_{2}$ PIII-treated polymer surface may possess antibacterial properties, although we have not observed this characteristic with the $\mathrm{O}_{2}$ PIII-treated polymer surface (Figure 2a). Previous studies have reported that polymer surfaces with nitrogen-containing functional groups have excellent antibacterial properties [11]. However, the molecular mechanism underlying the antibacterial characteristics has not been elucidated.

The behavior of osteoblasts is dependent upon the surface characteristics of materials, including surface morphology [12], surface energy [13], surface charge [14], 
and surface chemistry [15]. In general, plasma treatment can change the morphology and hydrophilicity of polymer surfaces. Although both the $\mathrm{N}_{2}$ PIII-treated polymer surface and $\mathrm{O}_{2}$ PIII-treated polymer surface had equivalent surface morphologies and hydrophilicities, the stimulating effects on osteoblast differentiation were observed only for the $\mathrm{N}_{2}$ PIII-treated polymer surface. Variation in the chemical nature of the surface functional groups is likely to be more critical in determining the behavior of osteoblasts, affecting other surface characteristics such as surface charge [14] and/or surface protein adsorption [13]. Future studies will be directed toward fully characterizing the differences between the sample surfaces and their interactions with the osteoblasts.

$\mathrm{N}_{2}$ PIII-treated polymer surface as described in our study is easily performed within a short period, with little impact on the intrinsic physical and chemical properties of the bulk polymer. More importantly, surface modification by this plasma technology is applicable to not only PE, but a variety of biodegradable polymers including poly(Llactic acid) and poly(e-caprolactone), both of which have an established safety record as bioresorbable polymers that are suitable for tissue engineering materials. Therefore, the $\mathrm{N}_{2}$ PIII-treated polymer surface may be useful in obtaining polymeric materials that possess antibacterial properties and the ability to accelerate bone tissue regeneration. 


\section{Conclusion}

This work demonstrates that the $\mathrm{N}_{2}$ PIII-treated PE surface has antibacterial properties and the ability to enhance osteoblast differentiation. The $\mathrm{N}_{2}$ PIII-treated polymer surface may be useful in bone tissue engineering. 


\section{Acknowledgements}

This work was supported by Grant-in-Aid for Scientific Research (JSPS postdoctoral fellowship) (19-07607) from the Japan Society for the Promotion of Science and partially by Hong Kong Research Grants Council (RGC) General Research Fund (GRF) No. CityU 112306. 


\section{References}

[1] D.S.W. Benoit, M.P. Schwartz, A.R. Durney, K.S. Anseth, Small functional groups for controlled differentiation of hydrogel-encapsulated human mesenchymal stem cells. Nat. Mater. 7 (2008), 816-823.

[2] C.J. Flaim, S. Chien, S.N. Bhatia, An extracellular matrix microarray for probing cellular differentiation. Nat. Methods 2 (2005), 119-125.

[3] P.K. Chu, B.Y. Tang, L.P. Wang, X.F. Wang, S.Y. Wang, N. Huang, ThirdGeneration Plasma Immersion Ion Implanter for Biomedical Materials and Research. Rev. Sci. Instrum. 72 (2001), 1660-1665.

[4] W. Zhang, Y.J. Luo, P.K. Chu, Biocompatibility of metal and gas plasma modified polyethylene with antibacterial properties. Acta. Biomater. 4 (2008), 2028-2036.

[5] H.Y. Wang, J.H. Ji, W. Zhang, J. Jiang, Y.H. Zhang, S.H. Pu, P.K. Chu, Osteoblast Behavior on Plasma-Treated Biodegradable Poly(Butylene Succinate). Acta. Biomater. 5 (2009), 279-287.

[6] A.J. Wagner, D.H. Fairbrother, F.A. Reniers, Comparison of PE surfaces modified by plasma generated neutral nitrogen species and nitrogen ions. Plasmas Polym. 8 (2003), 119-134.

[7] R.L. Nichols, I.I. Raad, Management of bacterial complications in critically ill patients: surgical wound and catheter-related infections. Diagn. Micr. Infec. Dis. 33 (1999), 121-130.

[8] A.D. Ranieri, A.S. Virdi, S. Kuroda, S. Shott, Y. Dai, D.R. Sumner, Local application of rhTGF-b2 modulates dynamic gene expression in a rat implant model. Bone 36 (2005), 931-940. 
[9] A.B. Ortiz-Magán, M.M. Pastor-Blas, T.P. Ferrándiz-Gómez, C. Morant-Zacarés, J.M. Martín-Martínez, Surface Modifications Produced by $\mathrm{N}_{2}$ and $\mathrm{O}_{2}$ RF Plasma Treatment on a Synthetic Vulcanized Styrene-Butadiene Rubber. Plasmas Polym. 6 (2001), 81-105.

[10] Y.L. Hsu, J.K. Chang, C.H. Tsai, Myricetin induces human osteoblast differentiation through bone morphogenetic protein-2/p38mitogen-activated protein kinase pathway. Biochem. Pharmacol. 73 (2007), 504-514.

[11] G.W. Charville, E.M. Hetrick, C.B. Geer, M.H. Schoenfisch, Reduced bacterial adhesion to fibrinogen-coated substrates via nitric oxide release. Biomaterials 29 (2008), 4039-4044.

[12] S. Mitragotri, J. Lahann, Physical approaches to biomaterial design. Nat. Mater. 8 (2009), 15-23.

[13] Y. Arima, H. Iwata, Effect of wettability and surface functional groups on protein adsorption and cell adhesion using well-defined mixed self-assembled monolayers. Biomaterials 28 (2007), 3074-3082.

[14] S. Nakamura, T. Kobayashi, M. Nakamura, K. Yamashita, Enhanced in vivo responses of osteoblasts in electrostatically activated zones by hydroxyapatite electrets. J. Mater. Sci. Mater. Med. 20 (2009), 99-103.

[15] D.F. Williams, On the mechanisms of biocompatibility. Biomaterials 29 (2008), 2941-2953. 


\section{Figure captions}

Table 1 Element ratios of $\mathrm{O} / \mathrm{C}$ and N/C in the surface of the samples determined by XPS.

Figure 1 High resolution XPS spectra of $\mathrm{C}_{1 \mathrm{~s}}$ of the surfaces of (a) PE control, (b) $\mathrm{O}_{2}$ PIII-treated polymer surface, and (c) $\mathrm{N}_{2}$ PIII-treated polymer surface, and (d) high resolution XPS spectrum of $\mathrm{N}_{1 \mathrm{~s}}$ of the surface of the $\mathrm{N}_{2}$ PIII-treated polymer surface.

Figure 2: a) Number of viable $E$. coli on the PE control, $\mathrm{O}_{2}$ PIII-treated polymer surface, and $\mathrm{N}_{2}$ PIII-treated polymer surface after incubating for 24 hours ( $\mathrm{n}=6, * *$ : $\left.\mathrm{p}<0.001\right)$. b) ALP and c) OC expressions in MC3T3-E1 cells on the PE control, $\mathrm{O}_{2}$ PIII-treated polymer surface, and $\mathrm{N}_{2}$ PIII-treated polymer surface after incubating for 4 days, $(n=3$, *: p < 0.05). d) ALP activity and e) OC content normalized to the total protein content of the MC3T3-E1 cells on the PE control, $\mathrm{O}_{2}$ PIII-treated polymer surface, and $\mathrm{N}_{2}$ PIIItreated polymer surface $(n=6, *$ : $p<0.05) . \quad O_{2}$ PIII: $\mathrm{O}_{2}$ PIII-treated polymer surface. $\mathrm{N}_{2}$ PIII: $\mathrm{N}_{2}$ PIII-treated polymer surface. 

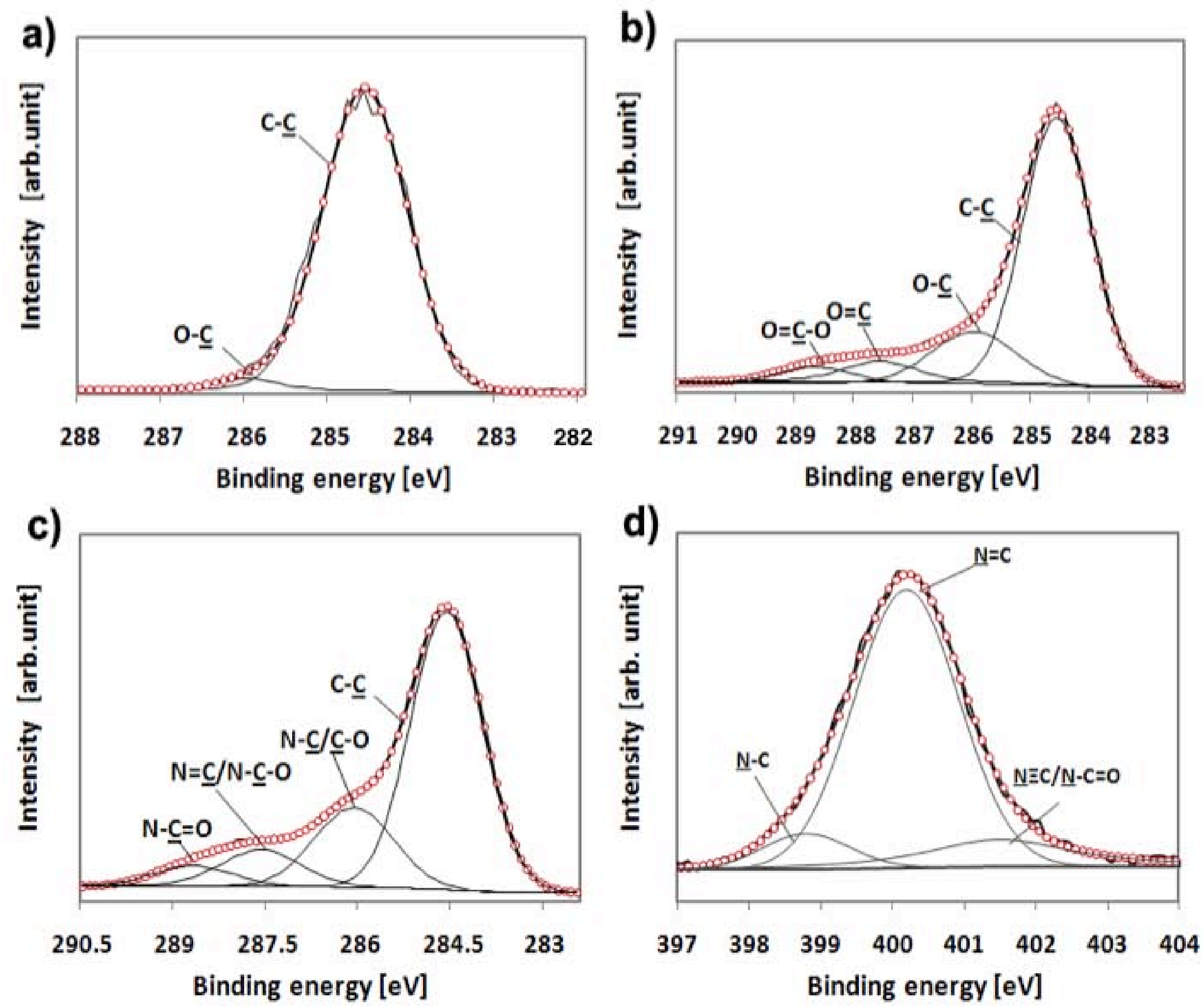

Figure 1 


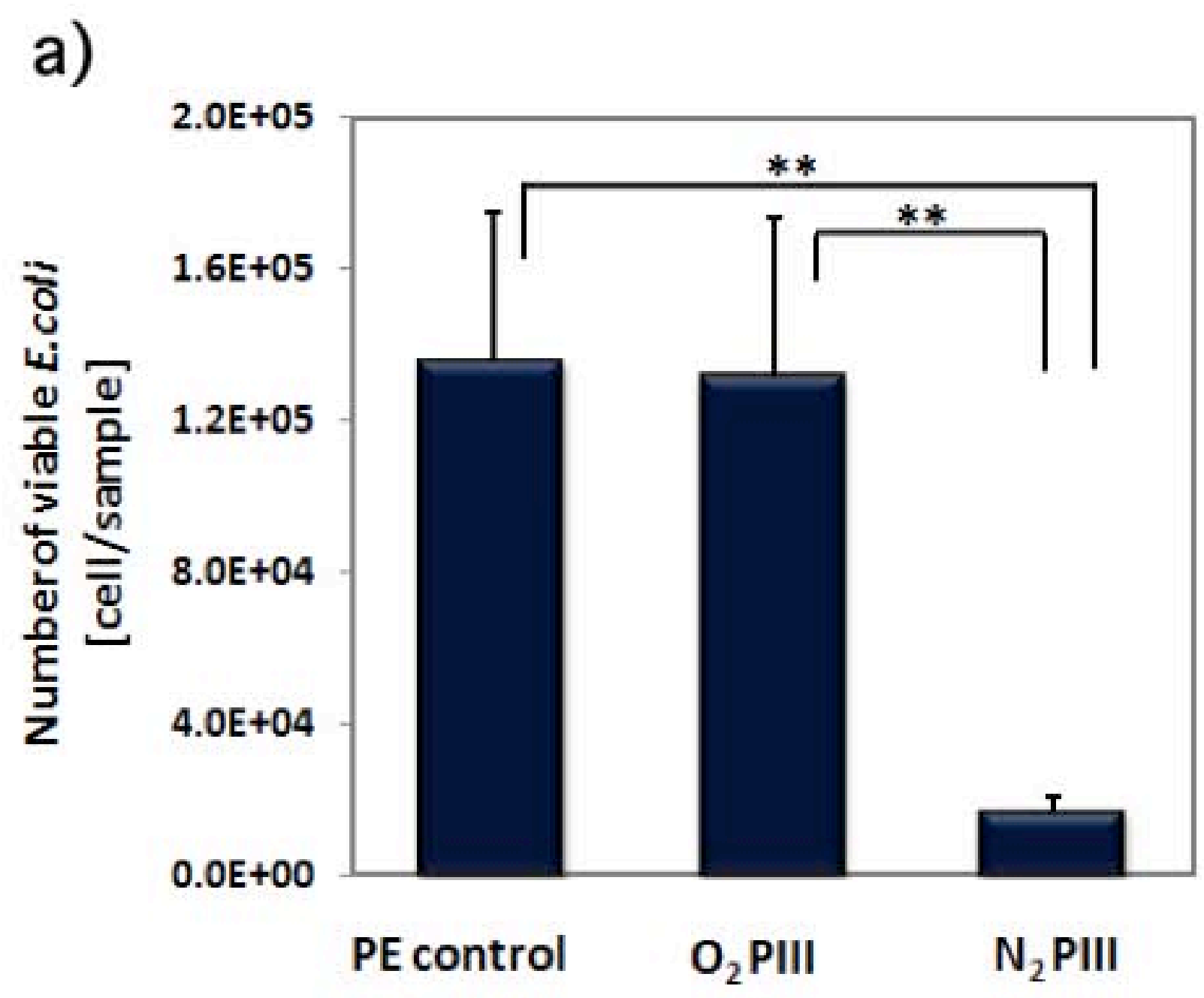

Figure 2 


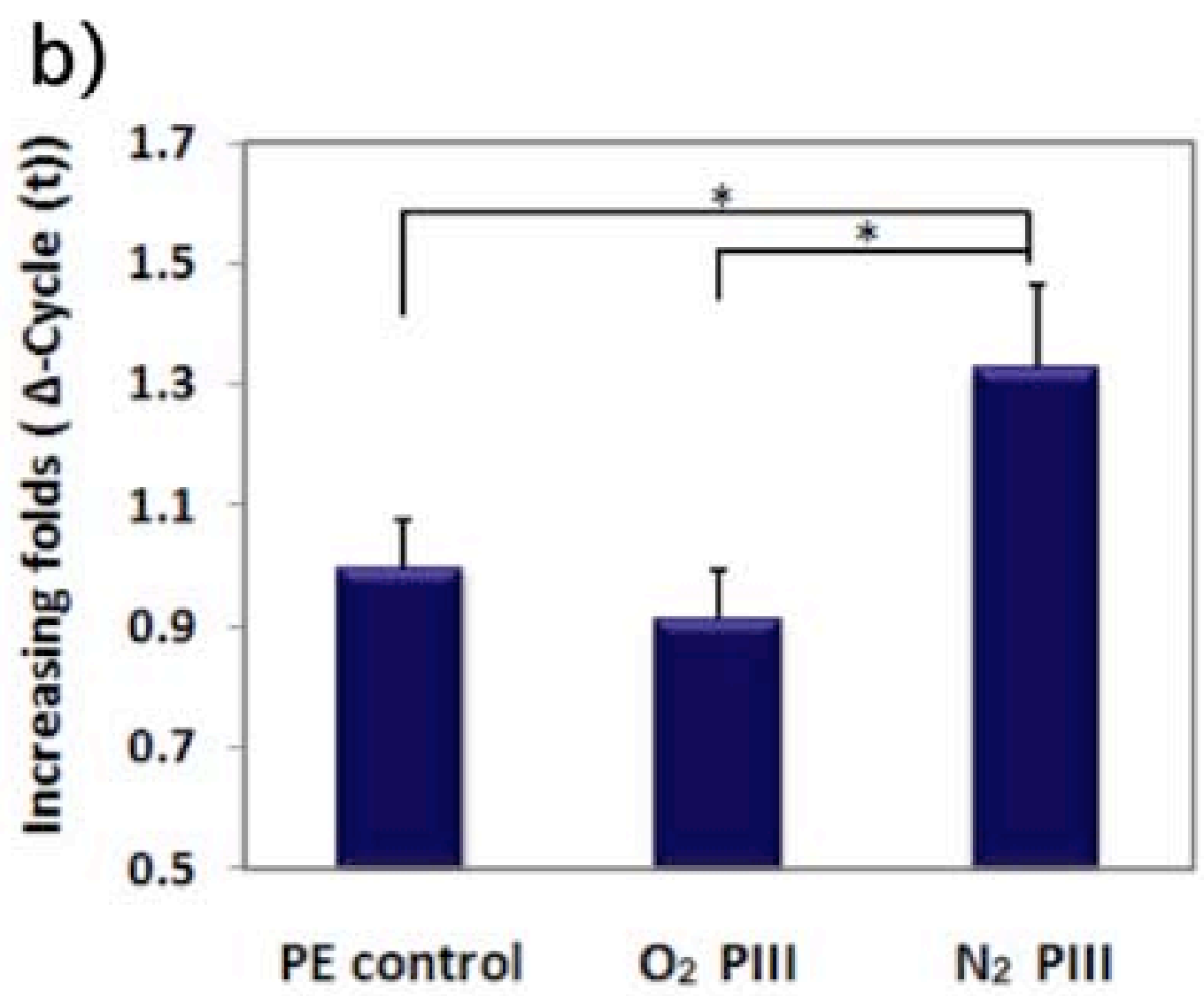

c)

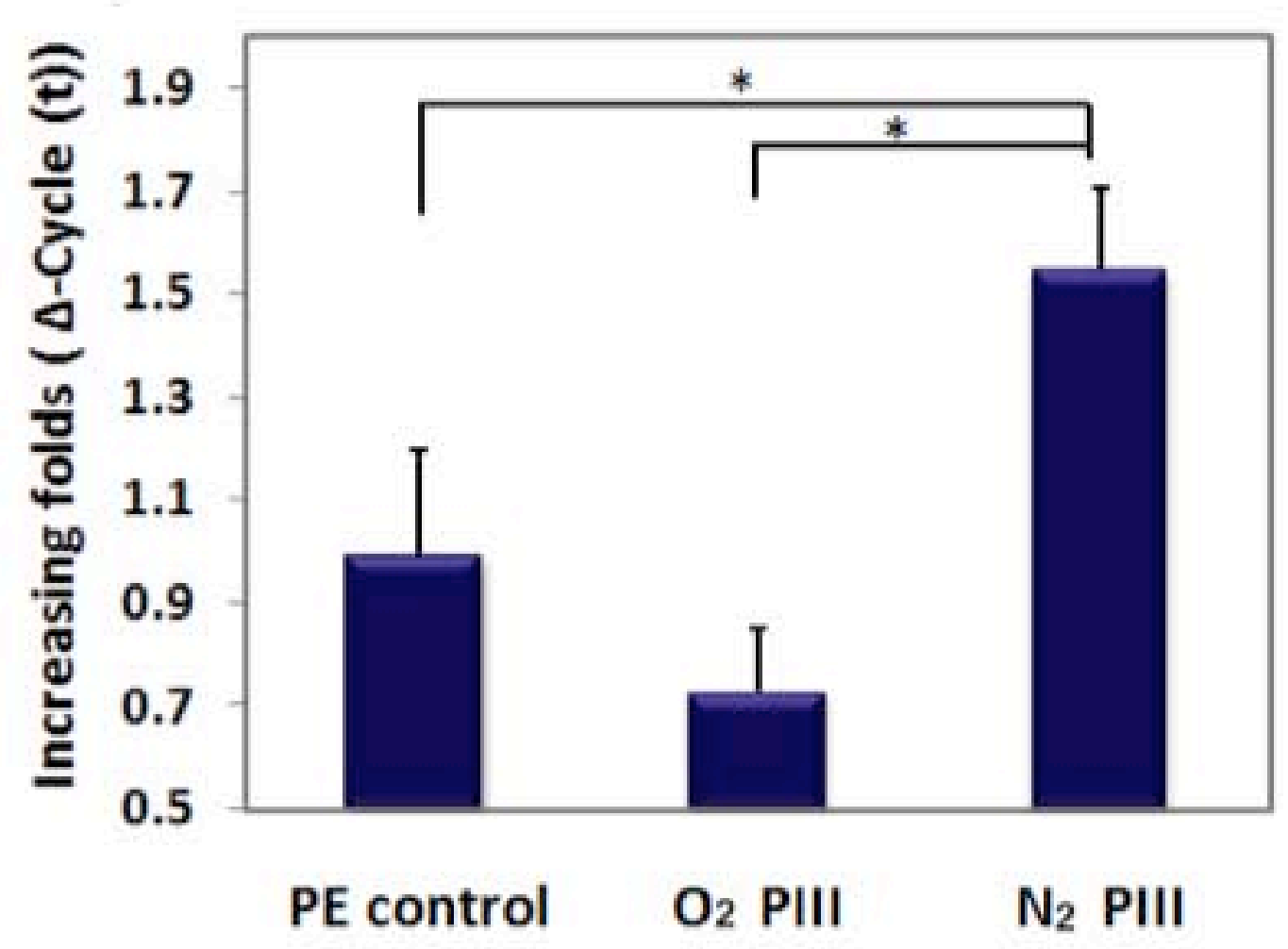

Figure 2 
d)

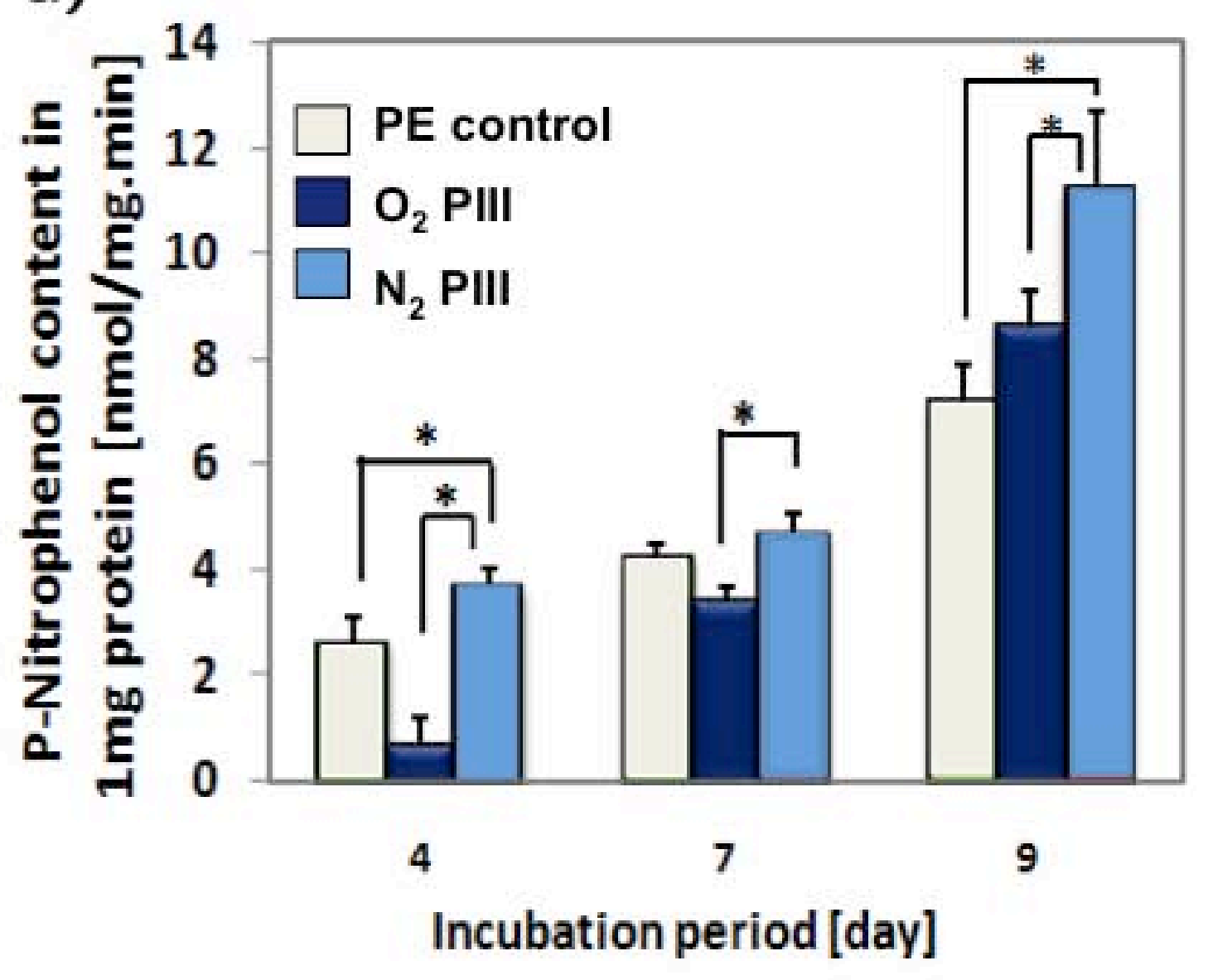

e)

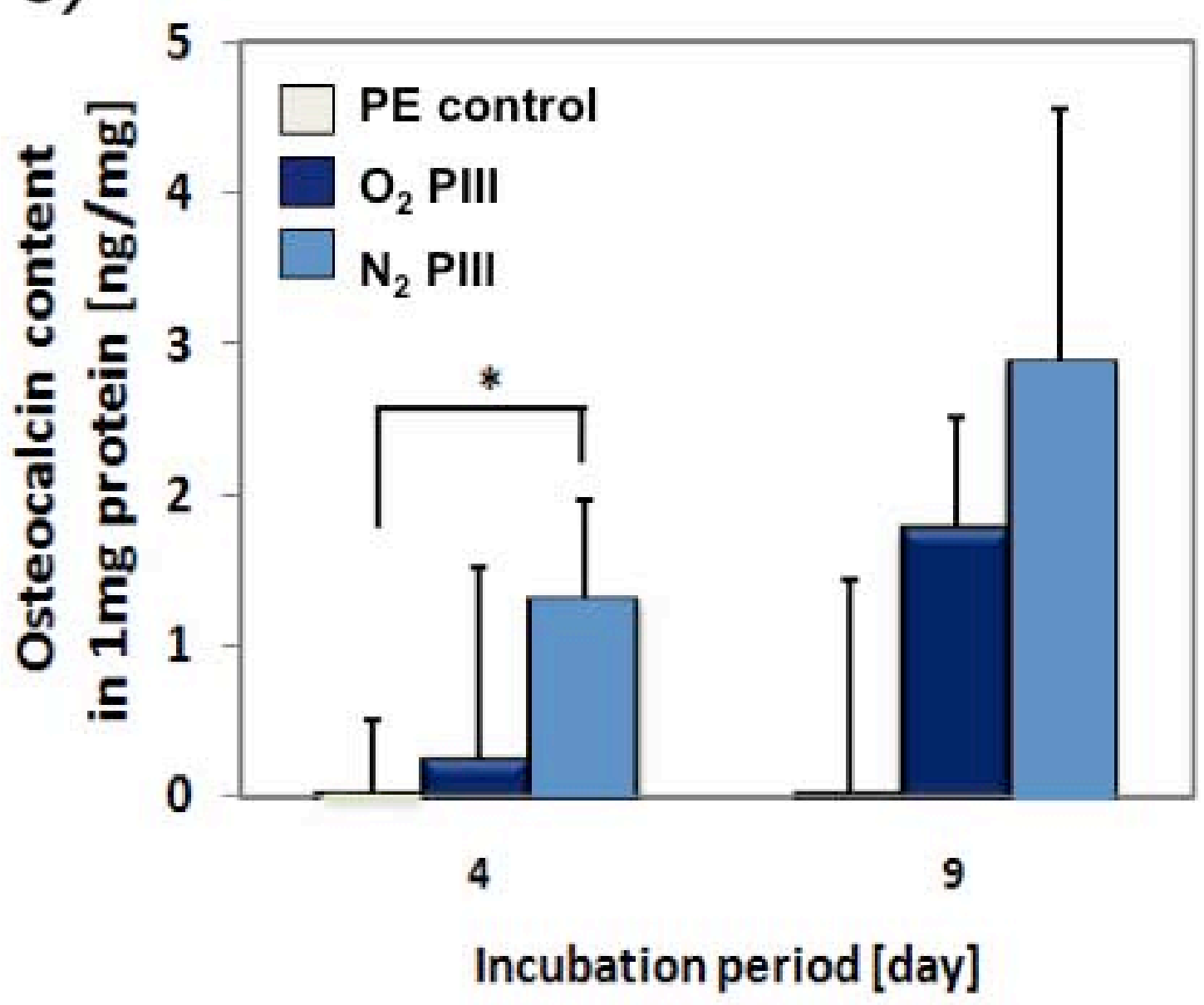

Figure 2 
Table 1

Element ratios of $\mathrm{O} / \mathrm{C}$ and $\mathrm{N} / \mathrm{C}$ on the surface of the samples

\begin{tabular}{c|cc}
\hline & \multicolumn{2}{|c}{ Element } \\
\cline { 2 - 3 } & $\mathrm{O} / \mathrm{C}$ & $\mathrm{N} / \mathrm{C}$ \\
\hline PE control & 2.4 & $\cdots$ \\
$\mathrm{O}_{2}$ PIII & 30.4 & 3.3 \\
$\mathrm{~N}_{2}$ PIII & 33.6 & 11.5 \\
\hline
\end{tabular}

